\title{
The Use of the Peripherally Inserted Central Catheter (Picc) in the Hospital Environment ${ }^{1}$
}

\author{
Graziella Gasparotto Baiocco² \\ Jefferson Luis Braga da Silva ${ }^{3}$
}

The study aimed to analyze the history of the use of the peripherally inserted central catheters in adult patients admitted to hospital from 2000 to 2007. The historical cohort approach was used with retrospective data collection from medical records of the Catheter Group of the Moinhos de Vento Hospital Association in Porto Alegre, RS, totaling 229 catheters inserted. The growth curve in the use of the PICC was from 1 catheter inserted in 2000 to 57 in 2007. The most prevalent pathology was oncology $(17.9 \%, n=41)$. In relation to the indications of use, antibiotic use prevailed $(54.1 \%, n=124)$. In the radiological confirmation the vena cava was prevalent $(68.1 \%, n=156)$. The use of the PICC in the hospital environment is expanding and nursing has a fundamental role in its insertion, maintenance and removal.

Descriptors: Catheterization, Central Venous; Nursing; Injetion, Intravenous.

\footnotetext{
${ }^{1}$ Article extracted from Master's Dissertation "A utilização do Cateter Central de Inserção Periférica no ambiente hospitalar", presented to Pontifícia Universidade Católica do Rio Grande do Sul, RS, Brazil.

${ }^{2}$ RN, M.Sc. in Medicine and Health Sciences, Professor, Universidade Feevale, Novo Hamburgo, RS, Brazil. E-mail: graziella@feevale.br, grazigasparotto@terra.com.br.

${ }^{3}$ Physician, Ph.D. in Orthopedics and Traumatology, Professor, Universidade Católica do Rio Grande do Sul, Porto Alegre, RS, Brazil. E-mail: jeffmao@terra.com.br.
}

Corresponding Author:

Graziella Gasparotto Baiocco

Universidade Feevale. Instituto de Ciências da Saúde.

RS 239 No 2755

CEP: 93352-000 Novo Hamburgo, RS, Brasil

E-mail: graziella@feevale.br. 


\section{A utilização do cateter central de inserção periférica (CCIP) no ambiente hospitalar}

O estudo objetivou analisar o histórico da utilização do cateter central de inserção periférica em pacientes adultos e internados, em ambiente hospitalar, de 2000 a 2007. Teve abordagem de coorte histórica, com coleta de dados retrospectiva em prontuários do Grupo de Cateteres da Associação Hospitalar Moinhos de Vento, em Porto Alegre, RS, totalizando 229 cateteres inseridos. A curva de crescimento na utilização do cateter central de inserção periférica (CCIP) foi de 1 cateter inserido em 2000 a 57 inseridos em 2007. A prevalência inerente à patologia foi a oncológica $(17,9 \%, n=41)$. Em relação às indicações ao uso, prevaleceu a antibioticoterapia $(54,1 \%, n=124)$. Na confirmação radiológica, a veia cava foi prevalente $(68,1 \%, n=156)$. Pode-se concluir que a utilização do CCIP no ambiente hospitalar está em expansão e a enfermagem tem papel fundamental na inserção, manutenção e sua remoção.

Descritores: Cateterismo Venoso Central; Enfermagem; Injeção Intravenosa.

\section{La utilización del catéter central de inserción periférica (CCIP) en el ambiente hospitalario}

El estudio objetivó analizar el histórico de la utilización del catéter central de inserción periférica en pacientes adultos e internados en ambiente hospitalario de 2000 a 2007. Tuvo abordaje de cohorte histórico con recolección de datos retrospectivo en fichas del Grupo de Catéteres de la Asociación Hospitalaria Molinos de Viento en Porto Alegre, RS, totalizando 229 catéteres inseridos. La curva de crecimiento en la utilización del CCIP fue de 1 catéter inserido en 2000 a 57 inseridos en 2007. La prevalencia inherente a la patología fue oncológica $(17,9 \%, n=41)$. En relación a las indicaciones de uso prevaleció la terapia con antibióticos $(54,1 \%, n=124)$. En la confirmación radiológica la vena cava fue prevalente $(68,1 \%, n=156)$. La utilización del CCIP en el ambiente hospitalario está en expansión y la enfermería tiene un papel fundamental en la inserción, manutención y remoción.

Descriptores: Cateterismo Venoso Central; Enfermería; Injecciones Intravenosas.

\section{Introduction}

The use of the peripherally inserted central catheter is expanding due to the positive results of its employment, and the use of biocompatible materials in the manufacture of the catheter provide better risk management with greater safety and comfort for the patient $^{(1)}$. The PICC is an intravenous device that allows infusion of solutions with extremes of $\mathrm{pH}$ and osmolarity, vesicant or irritant drugs and Total Parenteral Nutrition $(\text { TPN })^{(2)}$.

The main advantages of this catheter are its introduction at the bedside, inserted by qualified nurses, minimal pain reported at the time of insertion, and low rate of complications from its placement to its removal. To perform the procedure training of nurses is needed through courses offered mainly by the Nursing Societies, according to guidelines of the Infusion Nurses Society (INS) and the Center for Disease Control and Prevention $(C D C)$, agencies based in the United States of America(3-4).

This aim of this study was to report and analyze the history of the use of the Peripherally Inserted Central Catheter in adult patients admitted to the hospital since the beginning of their deployment, with the first catheter being inserted in 2000, until the year 2007. The specific aims were: to describe the profile of patients who used the PICC in the institution, throughout the 
study period; to know the main indications of the use of the PICC in these patients; to analyze the most frequent complications of patients who used the PICC; to verify the reasons for withdrawal of the PICC; to know the length of permanence of the PICC in these patients; and to verify the control of pain recorded in the chart at the time of catheter insertion.

\section{Methods}

Regarding the research, this was a historical cohort study with retrospective data collection, as it seeks to analyze the medical records of the patients who used the catheter in the past eight years. The cohort study has as a characteristic the time of monitoring the patients when they are exposed to the factor considered causative. It is considered the best type of epidemiological design, as it allows the researcher to calculate estimates of the incidence rates ${ }^{(5)}$.

The study was conducted at the Moinhos de Vento Hospital Association, a medium-sized hospital located in the city of Porto Alegre, Rio Grande do Sul, which treats insured and private patients, providing a total of three hundred and thirty inpatient beds. It has a Catheter Reference Group consisting of nurses qualified to insert PICCs since 2001. A convenience sample was used, collecting the data regarding all catheters inserted from 2000 to 2007, and totaled 229 catheters inserted in adults aged eighteen or over. Data collection occurred in February, March and April of 2009, from the protocols of records of the Catheter Reference Group, which has a monitoring form for each catheter inserted. In conjunction with this other necessary information was obtained by searching records of patients in the Medical Archive and Statistics Service (SAME). Regarding the data on the control of pain reported by the patient at the time of insertion of the PICC, the item which records the degree of pain on a numerical scale (used in the study institution) was analyzed, in which 'pain $=0$ ' is the absence of pain and 'pain $=10$ ' is the maximum degree of pain the patient can feel.

Data analysis had as an initial approach the descriptive statistics with simple and relative frequency distributions, as well as measures of position (mean and median) and of dispersion (standard deviation and interquartile range) to describe the variables age, pain and length of catheter use. Also in relation to the variables mentioned, the distribution of data was investigated, to identify those which showed a normal distribution (symmetric) using the Kolmogorov Smirnov test. For the investigation of differences between the proportions described in the analysis, the chi-square $\left(\chi^{2}\right)$ was used to compare proportions, assuming homogeneity between the categories compared. The data were treated statistically using the Statistical Package for the Social Sciences for Windows (SPSS) 13.0, adopting for decision criteria, the significance level $(\alpha)$ of $5 \%$.

Regarding the ethical aspects, the study was submitted to the Research Ethics Committee of the institution under study, and only after approval was the data collection initiated. The Commitment with the Use of Data Term was signed, by which the commitment to the data collected was assumed.

\section{Results}

In the initial sample, information on 231 patients was gathered, distributed between the years 2000 and 2007. However, as one of the inclusion criteria prevented the participation of patients under eighteen years of age, two patients aged sixteen and seventeen were excluded, thus, the final sample was composed of 229 events investigated.

Considering the distribution of the patients according to year, the highest concentration occurred in 2007 , representing $24.9 \%(n=57)$ of the sample, followed by the years 2004 , with $17.0 \%(n=39)$ and 2003 , with $16.2 \%(n=37)$ of the sample. With regard to age, the mean age was 61.5 years ( $S D=17.8$ years), and the minimum and maximum ages were 19 and 93 years respectively. When the approach was carried out through age groups, the prevailing group was aged between 70 to 79 years, which concentrated $26.6 \%$ $(n=61)$ of the patients. In the others, there were varying proportions of between $17.0 \%(n=39)$, which occurred in the age group 60 to 69 years, and $4.4 \%(n=10)$ in the patients 18 to 29 years of age. In the comparison of the percentages by age groups, the Chi-square test showed a statistically significant difference $\left(\chi_{\text {calc }}^{2}=44.428\right.$; $\mathrm{p}<0.001)$, indicating that the proportions of patients observed at ages 60 to 69 and 70 to 79 years showed significantly higher than the proportions presented in the other age groups of the study.

Regarding gender, males predominated, characterizing $70.7 \%(n=162)$ of the patients and, according to the Chi-square test $\left(\chi_{\text {calc }}^{2}=39.410\right.$; $\mathrm{p}<0.001)$, the proportion of men was significantly higher than the women $(29.3 \%)$ in this sample. The information relating to the pathologies, showed a higher occurrence in the group consisting of anemia, aplastic 
anemia, leukemia, HIV and lymphoma, representing $17.9 \%(n=41)$, a second group was formed by rectal cancer, fistulas, infection, intestinal obstruction and subocclusion, pancreatitis and peritonitis that occurred in $13.1 \%(n=30)$ of patients. A third group was formed by septic arthritis/fever, which occurred in $12.2 \%(n=28)$ of the sample.

Regarding the use of the PICC, antibiotic therapy was the predominant characterization, which was present in $54.1 \%(n=124)$ of the sample. The other uses indicated occurred in situations of chemotherapy, $20.1 \%$ $(n=46)$, serotherapy, with $7.9 \%(n=18)$, Total Parenteral Nutrition, observed in $6.6 \% \quad(n=15)$ and mannitol therapy which occurred in $4.8 \%(n=11)$ of patients. Also, uses for the PICC with lower frequencies were observed in situations such as transfusions, analgesic and other infusions (antiarrhythmic, anticoagulant and corticosteroid). It may be observed that in agreement with the literature studied the use of the PICC was for the infusion of antibiotics and chemotherapeutics. A study researched in the literature, found that the main indication of the PICC use, was to administer chemotherapeutics, comprising $80 \%$ of the sample, followed by antibiotic therapy and parenteral nutrition. Thus, the PICC has demonstrated itself as a safe (due to its high strength and durability) and efficient device in the administration of chemotherapeutic drugs over long periods ${ }^{(6)}$.

Using the PICC becomes appropriate when intravenous therapy is for five days or more, it should not be used as a first option on all hospitalized patients, but it is a safe and more comfortable alternative for those patients who require many blood collections, intravenous therapy over a long period or have difficult venous $\operatorname{access}^{(7)}$.

Regarding the vessel accessed, it was found that in $62.9 \%(n=144)$ of the patients the basilic vein was accessed, and, according to a Chi-square test $\left(\chi_{\text {calc }}^{2}=15.201 ; p<0.001\right)$, this ratio differs significantly from that observed among the patients who had the cephalic vein accessed, $37.1 \%(n=85)$. In relation to the use of the basilic vein for insertion of the PICC, it was identified that this was the vein most widely used due to its better palpation, visualization and better catheter migration.

With regard to pain evaluation, it was found that this characteristic was not addressed in the years 2000 to 2003 , thus $27.5 \%(n=63)$ of the patients investigated did not present this information. As for the remaining $72.5 \%(n=166)$ of patients, considered as valid cases for analysis, $54.2 \%(n=90)$ were characterized by the absence of pain and, as a result of the Chi-square $\left(\chi_{\text {calc }}^{2}=1.181 ; p=0.277\right)$, this proportion did not differ significantly from the proportion of those investigated that said they felt pain, $45.8 \%(n=76)$. The need for measuring the degree of patient pain during insertion of the PICC is a key factor in the evaluation of the level of comfort that the patient presents during the procedure. Authors report that PICCs offer a lesser degree of discomfort during insertion than other central devices $^{(6)}$.

In the information regarding the complications during catheter insertion, it can be verified that all patients presented some type of difficulty. Much of the sample, $75.1 \%(n=172)$, presented difficulties of insertion for one puncture, followed by difficulties of insertion for two punctures, which occurred in $13.5 \%$ $(n=31)$ of the patients sampled. Comparing the proportions of the difficulties during catheter insertion, the Chi-square test indicated a statistically significant difference $\left(\chi_{\text {calc }}^{2}=315.472 ; p<0.001\right)$, indicating that the proportion of difficulties that occurred for one puncture was significantly higher than the difficulties presented for the other numbers of punctures. Considering the evaluation of complications during insertion of the PICC, patients without this characteristic prevailed, $79.0 \%(n=181)$, and this proportion was significantly higher than the proportion of the group of patients who develop any complications during catheter insertion $\left(\chi_{\text {calc }}^{2}=216.559, p<0.001\right)$. In relation to the group of patients in which some kind of complication during insertion of the PICC was detected, 52.1\% $(n=46)$ of the situations were characterized as difficult migration, in $35.4 \%(n=24)$ the catheter did not migrate, and in $10.4 \%(n=5)$ bleeding occurred.

With respect to the information of radiologic confirmation of the PICC, the vena cava showed prevalence among those investigated and was observed in $68.1 \%(n=156)$ of the patients, followed by the subclavian vein, with $16.2 \%(n=37)$. In agreement with the framework studied, the indication of the position of the PICC in which its distal end is in the superior vena cava, the sample achieved a suitable index of over $68 \%$ of its catheters well-positioned. Still, on the radiological confirmation of the PICC, responses were seen less frequently that referred to the axillary and brachial veins - both representing $2.2 \%(n=5)$, the innominate vein, $1.7 \%(n=4)$ and the jugular/subclavian, $0.9 \%(n=2)$, with $7.9 \%(n=18)$ of medical records where catheters that did not migrate adequately. 
With regard to complications during the use of the catheter, it was observed that $74.2 \%(n=170)$ of the patients had no complications and, according to the Chisquare test $\left(\chi_{\text {calc }}^{2}=53.803 ; p<0.001\right)$ this proportion was significantly higher than the proportion of the group of patients who presented some complication during the use of the catheter, $25.8 \%(n=59)$. The incidence of complications encountered in a study of the literature varied between $5 \%$ and $26 \%$ in peripherally inserted central catheters. Its rate is considered low when compared to that observed in peripheral catheters, where the incidence reaches $65 \%{ }^{(8)}$. In the patient group that was characterized as presenting some complication during the use of the PICC, the more prevalent were related to: the situation in which the catheter did not migrate, $28.8 \% \quad(n=17)$; fever, $20.3 \% \quad(n=12)$; obstruction, $15.3 \%(n=9)$; and traction, 10.2\% $(n=6)$. Also in relation to the group of patients who presented complications during the use of the PICC, there were $6.8 \%(n=4)$ of complications classified as others, which included the answers pulled out, folded, pseudo-phlebitis and resistance.

This study also evaluated the duration of catheter use, calculating that, of the total surveyed, $9.2 \%$ $(n=21)$ presented use time of zero days, indicating that the catheter use did not progress. Whereas in the $90.8 \%(n=187)$ of the patients with duration of catheter use other than zero, the median was 13 days and the minimum and maximum durations were 2 and 85 days respectively. It was also found that $50 \%$ of the patients presented catheter use duration between 7 and 24 days, $25 \%$ presented durations longer than 24 days, and $25 \%$ of the sample presented catheter use duration of less than or equal to 7 days. The distribution of patients in relation to four periods was also noted, and this showed that $40.9 \%(n=85)$ used the catheter between 1 and 10 days, and the longest period of use was observed in $5.3 \%$ of the patients, that used the catheter for over 30 days. In accordance with the literature studied the PICC should be used for a period of over 5 days of intravenous therapy.

Of the reasons that led to catheter removal, withdrawal due to patient discharge prevailed, which occurred in $52.4 \%(n=120)$ of the sample, followed by cases of fever, $8.7 \% \quad(n=20)$, this situation may have been related to the profile of patients who used the PICC being patients with oncological problems or immunocompromised, thus favoring the occurrence of infectious complications, non-migration, $8.3 \%(n=19)$, obstruction, $7.4 \%(n=17)$, and death, $4.4 \%(n=10)$.

\section{Discussion}

Based on the number of insertions that occurred in each year, a significant reduction in the number of complications after insertion of the PICC can be observed, which fell from $56.5 \%$ in 2002 to $6.3 \%$ in 2007. According to the Fisher's Exact test by Monte Carlo simulation $(p<0.001)$, it was found that the initial years (2000 to 2003) were associated with the presence of complications, whereas in later years (2004 to 2007), the association was with the absence of complications after using the PICC. Furthermore, it was found that the proportion of complications after use is becoming significantly smaller as the years pass, the result obtained from analyzing the linear-by-linear association $(p<0.01)$. In another study it was found that, in agreement with the results of this research, the PICC was considered a safe vascular access device, which allows the administration of fluids and medications that cannot be infused through peripheral access ${ }^{(8)}$. Regarding the proportion of complications during the insertion of the PICC, this did not present a pattern of behavior too accentuated, however it can be observed that in 2002, of the 23 patients treated, 30.4\% $(n=7)$ presented complications; in 2007, of the 80 procedures, $17.5 \%$ $(n=14)$ had complications while using the PICC. Despite the observed variations, they showed no statistically significant association or linear trends ( $p>0.05)$.

Evaluating the possible existence of relationships between some of the variables considered in the study and the vessel accessed, borderline significance was detected $(p=0.068)$ in the comparison with age, given that the patients who had the cephalic vein as the vessel accessed (mean=64.3; SD=18.5) tend to present a significantly higher mean age than the mean age of patients who had the basilic vein as the vessel accessed (mean=59.8; $\mathrm{SD}=17.3$ ).

Regarding the use of the catheter, in this study antibiotic administration was observed in $54.1 \%$ of the sample, and is in agreement with another study in the literature which reports that the majority (70\%) of the catheters studied were for the administration of an antibiotic, varying the combination of one to four types $^{(9)}$. In another study carried out with 496 catheters, the authors found the infusion of antibiotics in $49.8 \%$ of catheters studied(10).

An expressive variability was also observed in the comparison of vessel accessed and presence or absence of complications during the insertion of the PICC, indicating a trend of statistically significant association $(p=0.106)$, 
suggesting that the presence of complications may be associated with the cephalic vein. In connection with this association, the odds ratio was obtained, and it was found that the patients with access through the cephalic vein were 1.4 times more likely to have complications during insertion of the PICC than patients who had the basilica vein accessed ( $\mathrm{CI}$ : 0.9-2.0).

In the present study in $68.1 \%$ of the catheters inserted the radiological position of the catheter showed that its distal tip was found in the superior vena cava, in agreement with studies found in the literature that refer to the successful insertion of the PICC being obtained when the tip the catheter is positioned centrally, i.e. in the superior vena cava. If the tip moves beyond the superior vena cava, traction maneuvers will be applied to reposition the catheter ${ }^{(11)}$. Centrally placed catheter tips are associated with low complication rates compared to non-central catheters ${ }^{(12)}$. Thus, maintenance of the catheter tip in a central position is of paramount importance to reduce the risk of complications arising from the use of this device ${ }^{(13)}$.

Assessing the duration of use of the PICC in relation to pain, difficulties and complications in the use of the catheter, in the comparison between patients with and without pain, the durations of use were statistically similar, indicating that, regardless of the presence or absence of pain, in durations of use of the PICC the medians were equal between the two groups $(p>0.05)$. Comparing the duration of PICC use with the difficulties of insertion for one, two or three punctures, no statistically significant difference was detected $(p>0.05)$, suggesting that, regardless of the number of punctures used, the duration of PICC use should be similar. As for the comparison between the duration of PICC use and the presence and absence of complications during catheter insertion, a statistically significant difference was detected, in that the patients with complications had durations of catheter use significantly lower than the group of patients with absence of complications during PICC insertion $(p<0.05)$. It can be verified that the group of patients that did not present complications during insertion showed durations of use greatly varying in amplitude, reaching approximately 85 days, whereas in the group that presented complications the maximum duration was approximately 60 days.

For the variable referring to groups of pathologies observed in the study, those that were most prevalent $(n \geq 6)$, the comparisons with complications during catheter insertion showed no statistically significant association $(p>0.05)$, indicating that regardless of the presence or absence of complications the distribution of patients was similar. This same situation was observed when comparing the groups of pathologies in relation to complications during PICC use, where, in spite of variations in the distribution of patients, these were not statistically significant ( $p>0.05)$.

\section{Conclusion}

This study achieved its proposed aims, because to seek to report historic use of PICC in the hospital environment has become of paramount importance so that the positive points of this device, that always had its most widespread use in the neonatology area, can be shown through evidence, as the institution studied inserted 229 catheters in adult patients during the eight year period of the study.

Primarily, the importance should be clear of the nursing team which have mobilized and created a Catheter Group, always active and that can through meetings, perfecting and training of the teams, develop protocols and routines so as to disseminate the use of the PICC.

Through the data collected in this study it can be concluded that the PICC is a trusted device for different types of intravenous infusions that are necessary in both the domicile and hospital environments, because many of the patients surveyed completed their therapy as home care.

Further studies will always be required to seek and continue to update the thematic and perhaps to provide a better update regarding the costs related to the PICC when compared with the different types of devices that exist in the healthcare market.

\section{References}

1. Freitas LCM. Conceitos teóricos básicos para instalação e manuseio de cateter venoso central de inserção periférica (CCIP). Rio de Janeiro: Ministério da Cultura; 2003.

2. Camara D. Minimizing risks associated with peripherally inserted central catheters in the NICI. MCN Am J Matern Child Nurs. 2001;26(1):17-21.

3. Sociedade Brasileira de Enfermeiros de Terapia Intensiva (SOBETI). Curso de Qualificação em Inserção, Utilização e cuidados com o CCIP Neonatologia/Pediatria e Adultos. São Paulo; 2004.

4. Center for Disease Control and Prevention (CDC). Guidelines for the prevention of intravascular catheter related infection. MMWR. 2002;51:1-32. 
5. Gil AC. Como elaborar projetos de pesquisa. $4^{a}$ ed. São Paulo: Atlas; 2002.

6. Di Giacomo M. Comparison of three peripherally-inserted central catheters: pilot study. British J of Nurs. 2009;18(1):8-16.

7. Periard D, Monney P, Waeber G, Zurkinden C, Mazzolai L, Hayoz $D$, et al. Randomized controlled trial of peripherally inserted central catheters vs. peripheral catheters for middle duration in-hospital intravenous therapy. J Thromb Haemost. 2008;6:1281-8

8. Jesus VC, Secoli SR. Complicações acerca do cateter venoso central de Inserção Periférica (PICC). Cienc Cuid Saúde. 2007;6(2):252-60.

9. Machado AF, Pedreira MLG, Chaud MN. Estudo prospectivo, randomizado e controlado sobre o tempo de permanência de cateteres venosos periféricos em crianças, segundo três tipos de curativos. Rev. Latino-Am. Enfermagem. 2005 maio-junho; 13(3):291-8.
10. Foster L, Wallis M, Paterson B, James H. A descriptive study of peripheral intravenous catheters in patients admitted to a pediatric unit in one australian hospital. J Infus Nurs 2002;25(3):159-67.

11. Fricke BL, Racadio JM, Duckworth T, Donnelly LF, Tamer RM, Johnson ND. Placement of peripherally inserted central catheters without fluoroscopy in children: initial catheter tip position. Radiology. 2005;234(3):887-92.

12. Racadio JM, Doellman DA, Johnson ND, Bean JA, Jacobs BR. Pediatric peripherally inserted central catheters: complication rates related to catheter tip location. Pediatrics. 2001;107(2):E28.

13. Camargo PP, Kimura AF, Toma E, Tsunechiro MA, Localização inicial da ponta do cateter central de inserção periférica (PICC) em recém-nascidos. Rev Esc Enferm USP 2008;42(4):723-8.

Received: Dec. $13^{\text {th }} 2009$

Accepted: Sep. $30^{\text {th }} 2010$ 